\section{Reliability on timber columns under fire situation}

\section{Auro Cândido Marcolan Júnior, Poliana Dias de Moraes}

Graduate Program in Civil Engineering, Federal University of Santa Catarina, Florianópolis, Brazil

\begin{abstract}
Timber structures in fire situation are subject to intrinsic uncertainties from the material and the actions on the structure and their probabilistic behavior has not being studied exhaustively. In this paper, four limit state equations using the reduced cross-section method are developed for timber columns in fire situation. The security criteria taken into account in these equations are the compression, the lateral stability and the combined bending and compression, according to the NBR 7190:1997 standard. The structural reliability analysis of five simply supported timber columns with rectangular cross-section in fire situation and different base and height ratios where performed using the first order reliability method. The overall probability of failure of the column was obtained by associating the failure criteria in a series system. The reliability behavior of the different base to height ratios was evaluated, leading to different results for the distinct ratios and the criteria used. Also, a sensitivity analysis was performed indicating the timber charring rate as the most important random variable in the reliability analysis for these limit state equations.
\end{abstract}

\section{Introduction}

For the determination of the resistance of timber structural elements in a fire situation, there are simplified and advanced methods. In the simplified methods, the evaluation is carried out by the reduced cross-section method or by the reduced properties method. ${ }^{1}$ In the reduced crosssection method, the reduction is determined using the charring rate of the timber and the fire resistance is calculated using the residual cross-section. ${ }^{1}$ In the reduced properties method, besides the reduction of the crosssection by the charring, the modification of the mechanical properties of the material is taken into account by the increase of the internal temperature of the element. ${ }^{1}$ In the advanced methods, the evaluation is performed using the finite element method and the thermomechanical properties as func- tions of temperature. ${ }^{1}$ The safety of structural elements in normal and in fire situations is estimated by risk assessment methods that use limit state equations. ${ }^{1}$ Current standards ensure it, by using partial factors, which are calibrated through the structural reliability models, allowing engineers to work with semi-probabilistic problems, but still maintaining acceptable levels of reliability. ${ }^{2}$ In the literature, few works are found about structural reliability of timber structures. Kohler ${ }^{3}$ developed probabilistic models to describe timber properties in normal temperature. Vaidogas and Juoceicius ${ }^{4}$ presented a general approach to the reliability of a timber structure exposed to fire while Cheung et al. ${ }^{5}$ and Clancy ${ }^{6}$ developed procedures for the estimation of the probability of failure and failure time of beams and light-timber framed walls, respectively. There is a lack of studies involving the reliability of timber columns. In this paper, the influence of the base to height ratio $(B / H)$ and the random variables on the probability of failure of timber column is evaluated in fire situation. The limit state equations are derived from the reduced cross-section method, considering the criteria of compression, lateral stability and combined bending and compression, according to the NBR 7190:1997 standard. ${ }^{7}$ Additionally, a case study of a timber column subjected to a uniformly distributed lateral loading and a vertical loading is carried out.

\section{Materials and Methods}

\section{Timber column in fire situation}

In a fire situation, a timber column presents cross-section reduction due to wood charring, leading to reduction in load capacity during the fire exposure time. The load capacity depends on the residual cross-section, which can be obtained by subtracting the carbonized layer from the original cross-section, as established by the reduced cross-section method. ${ }^{1}$ For a rectangular column (Figure 1), with four faces exposed to the fire and neglecting the rounding of the edges, the dimensions of the residual cross-section as a function of the time of fire exposure are calculated by Eqs. 1 and 2 .

$$
\begin{aligned}
& b=B-\left(2 \cdot \beta_{\text {char }} \cdot t\right), \\
& h=H-\left(2 \cdot \beta_{\text {char }} \cdot t\right) .
\end{aligned}
$$

\section{Structural reliability. First order reliability method}

The objective of the structural reliability is to quantify and to evaluate the safety of
Correspondence: Auro Cândido Marcolan Júnior, Graduate Program in Civil Engineering, Federal University of Santa Catarina, Rua João Pio Duarte, s/n, Córrego Grande, Mailbox 476, 88040900 Florianópolis, SC, Brazil.

Tel.: +55.48.3721.9370.

E-mail: auro.marcolan@yahoo.com.br

Key words: Structures, Reliability; Timber; Columns; Fire.

Contributions: the authors contributed equally.

Conflict of interest: the authors declare no potential conflict of interest.

Funding: the authors thank the Brazilian Research Council (CNPq) for sponsoring this research through the grant number 148970/2016-8

Conference presentation: part of this paper was presented at the 4th Ibero-Latin American Congress on Fire Safety (4 ${ }^{\circ}$ CILASCI), 2017 Oct 9-11, Recife, Brazil.

Received for publication: 2 December 2017 Revision received: 5 June 2018.

Accepted for publication: 3 July 2018

This work is licensed under a Creative Commons Attribution 4.0 License (by-nc 4.0).

(C) Copyright A.C. Marcolan Júnior and P.D. de Moraes, 2018

Licensee PAGEPress, Italy

Fire Research 2018: 2:51

doi:10.4081/fire.2018.51

structures based on the probability theory, by calculating failure probabilities related to the structural system. The performance requirements of the structural systems can be defined in the form of limit state equations, in order to quantify the probability of failure of these requirements. ${ }^{2}$ Using the First Order Reliability Method (FORM), ${ }^{2}$ reliability problems are solved approximately by the linearization of the limit state equations. Such approximation is calculated on the so-called design point, defined as the point on the limit state equation with the shortest distance to the origin. This distance is usually represented by $\beta$ and called reliability index.

The probability of failure of the structural systems can be calculated using the standard normal cumulative distribution function $\Phi($.$) and the reliability index \beta .^{2,8,9}$ Thus the approximate probability can be defined by:

$P_{f}=\Phi(-\beta)$.

Structural design for fire safety presents 
more uncertainty than for normal temperature conditions. ${ }^{1}$ According to Buchanan and Abu, ${ }^{1}$ the strength reduction factor is derived by code writers to ensure in a fire situation a target reliability index $\beta$ between 2.00 and 3.00. In this paper, it is considered equal to 2.00 .

\section{Reliability evaluation of series sys- tems}

Systems composed by serially associated components, also known as chain systems, are those in which the weakest component failure leads to system failure. ${ }^{9}$ If an event $E_{\mathrm{i}}$ corresponds to the failure of the $\mathrm{i}^{\text {th }}$ series component, considering $n$ components, the system failure event $(F)$ is given by Eq. 4 . More information about reliability evaluation of series systems can be found in Sorensen. ${ }^{9}$

$$
F=E_{1} \cup E_{2} \cup E_{3} \cup \ldots \cup E_{n}=\cup_{i=1}^{n} E_{i} .
$$

\section{Limit state equations}

According to NBR 7190:1997 standard, ${ }^{7}$ for the design of a timber column subjected to transverse and to axially centered loads, the criteria of compression, lateral stability and combined bending and compression are considered. These criteria were used to derive four limit state equations, which were applied to the reliability analysis. The equations were adapted for the design of columns in fire situation by the reduced cross-section method, ${ }^{1}$ since current version of the Brazilian standard ${ }^{7}$ is only used for the design of timber structures in normal temperatures. In a recently proposed NBR 7190 draft, ${ }^{10}$ design prescriptions concerning fire situation were included. The compression limit state is represented by Eq. 6 and the combined bending and compression limit state is given by Eq. 8 . The lateral stability limit state is considered in three different situations: short column, medium slender column and slender column. The three criteria are required during the design process. The compression criterion of the column is presented by Eq. 5, where the compression stress is caused by the axial loads $G+Q$. Eq. 6 is the resulting limit state equation, where $X_{\mathrm{M}}$ is a random variable, which represents the model uncertainties.

$$
\begin{gathered}
\sigma_{N c} \leq f_{c 0}, \\
g_{1}=\left(f_{c 0}-\frac{(G+Q)}{b \cdot h}\right) \cdot X_{M} .
\end{gathered}
$$

The combined bending and compression criterion, considering that the bending moment is applied in one direction, is given

$$
\left(\frac{\sigma_{N c}}{f_{c 0}}\right)^{2}+\frac{\sigma_{M}}{f_{c 0}} \leq 1 \text { equation: }
$$

The limit state equation for the combined bending and compression criterion is given by

$$
g_{2}=1-\left(\left(\frac{G+Q}{b \cdot h \cdot f_{c 0}}\right)^{2}+\frac{w \cdot L^{2}}{8 \cdot W_{c} \cdot f_{c 0}}\right) \cdot X_{M}
$$

where

$$
W_{c}=\frac{I}{y_{c}} \text {. }
$$

The lateral stability is evaluated according to the slenderness ratio of the element. If the slenderness ratio is less than 40 , the column is considered short and the combined bending and compression criterion is only taken into account by Eq. 8 . For a slenderness ratio in the range of $40<\lambda \leq 80$, the column is considered medium slender and the lateral stability criterion is:

$$
\frac{\sigma_{N c}}{f_{c 0}}+\frac{\sigma_{M}}{f_{c 0}} \leq 1
$$

where the maximum bending stress is determined from the moment obtained by Eqs 11 to 17 .

$$
\begin{aligned}
& M=N \cdot e_{d}, \\
& e_{d}=e_{1} \cdot\left(\frac{F_{E}}{F_{E}-N}\right), \\
& F_{E}=\frac{\pi^{2} \cdot E_{c 0} \cdot I}{L_{0}^{2}}, \\
& e_{1}=e_{i}+e_{a}, \\
& e_{i}=\frac{(w) L^{2}}{8 \cdot(G+Q)}, \\
& e_{a}=\frac{L_{0}}{300},
\end{aligned}
$$

$$
e_{a} \geq \frac{d}{30} \text { and } e_{i} \geq \frac{d}{30}
$$

The limit state equation for the lateral stability criterion of a medium slender column is:

$g_{3}=1-\left(\left(\frac{G+Q}{b \cdot h \cdot f_{c 0}}\right)+\frac{(G+Q) e_{1} \cdot\left(\frac{F_{E}}{F_{E}-(G+Q)}\right)}{f_{c 0} \cdot W_{c}}\right) \cdot X_{M}$

For a slenderness ratio $\lambda>80$, the column is considered slender and the lateral stability criterion is also given by Eq. 10, but the bending moment is determinate using Eqs. 19 and 20

$$
\begin{gathered}
M=N \cdot e_{1, e f} \cdot\left(\frac{F_{E}}{F_{E}-N}\right), \\
e_{1, f}=\left(e_{i}+e_{a}+\left[e_{a} \cdot\left\{\exp \left[\frac{\Phi \cdot\left[G+\left(\psi_{1}+\psi_{2}\right) \cdot Q\right]}{F_{E}-\left[G+\left(\psi_{1}+\psi_{2}\right) \cdot Q\right]}\right]-1\right\}\right]\right)
\end{gathered}
$$

The limit state equation for the lateral stability criterion of slender columns is given by:

$g_{4}=1-\left(\left(\frac{G+Q}{b \cdot h \cdot f_{c 0}}\right)+\frac{(G+Q) \cdot e_{1, f} \cdot\left(\frac{F_{E}}{F_{E}-(G+Q)}\right)}{f_{c 0} \cdot W_{c}}\right) \cdot X_{M}$

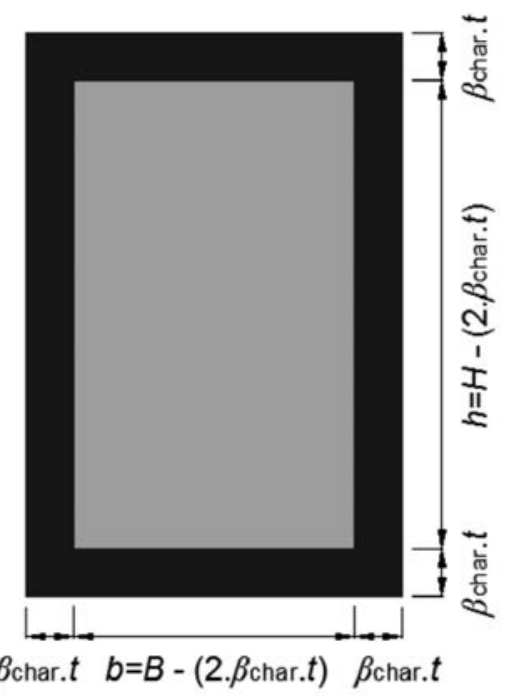

Figure 1. Charring of the cross-section. 


\section{Case study}

Structural reliability analyses were performed using the FORM ${ }^{2}$ implemented in the Risk Tools software developed by Mahsuli. ${ }^{11}$ The analysis results are: failure probabilities of the elements as a function of the time of fire exposure for the different design criteria presented, evaluation of the different column base to height ratios $(B / H)$ and a sensitivity analysis of the parameters, indicating the most influent random variables on the reliability analysis.

\section{Structural system of the timber columns}

In the analysis, the columns with length of $5.00 \mathrm{~m}$ are simply supported and have a rectangular cross-section of $0.40 \mathrm{~m}^{2}$, but differing on the $B / H$ ratios. The ratios considered were $1.00,0.80,0.60,0.40$ and 0.20 , resulting in cross-sections of $20 \mathrm{~cm} \times 20$ $\mathrm{cm}, 18 \mathrm{~cm} \times 22 \mathrm{~cm}, 16 \mathrm{~cm} \times 25 \mathrm{~cm}, 13 \mathrm{~cm}$ $\times 31 \mathrm{~cm}$ and $9 \mathrm{~cm} \times 45 \mathrm{~cm}$. They were subjected to $G$ and $Q$ vertical loads. The distributed lateral load $w$ is due to the dynamic wind pressure and is applied either in direction $x$ or in direction $y$ (Figure 2).

The four sides of the cross-section were considered exposed to fire. The wood charring rate is constant and reduces the crosssection without causing corner rounding, due to the model simplification. The column slenderness ratio was evaluated at each $1 \mathrm{~min}$ of fire exposure interval in the range of 0 to $200 \mathrm{~min}$.

\section{Random variables parameters}

The probabilistic input parameters of the random variables, mechanical properties of the timber, permanent and variable actions, were obtained from Cheung et al. ${ }^{5}$ The wood considered is Eucalyptus citriodora with moisture content of $12 \%$. The average load used was $50.00 \mathrm{kN}$ for the permanent action $(G)$ and $125.00 \mathrm{kN}$ for the variable action $(Q)$.

The dynamic wind pressure was calculated assuming the characteristic wind speed $\left(V_{\mathrm{k}}\right)$ of $45 \mathrm{~m} / \mathrm{s}$, according to the NBR 6123:1988 standard ${ }^{12}$ and is given by:

$$
w=0.631 \cdot V_{k}^{2},
$$

resulting in $w=1.28 \mathrm{kN} / \mathrm{m}^{2}$. Using a span length of $5.0 \mathrm{~m}$, the value of $w$ is 6.39 $\mathrm{kN} / \mathrm{m}$. The coefficient of variation for the characteristic wind velocity was obtained from the JCSS: Probabilistic Model Code. ${ }^{13}$

The random variable associated to the model uncertainties $\left(X_{\mathrm{M}}\right)$ is described in Kohler $^{3}$ and is applied to uncertainties related to material parameters (such as compression strength along the grain, modulus of elasticity), geometric deviations from specified dimension, load duration and moisture effects. The random variables statistical properties are summarized in Table 1. The creep coefficient $(\Phi)$ was 0.8 , for permanent or long duration loading and moisture class 1 and $2 .^{7}$ The values of $\psi_{1}$ and $\psi_{2}$ were 0.30 and 0.20 , respectively. ${ }^{7}$ The sum of these factors should not be greater than 1 .

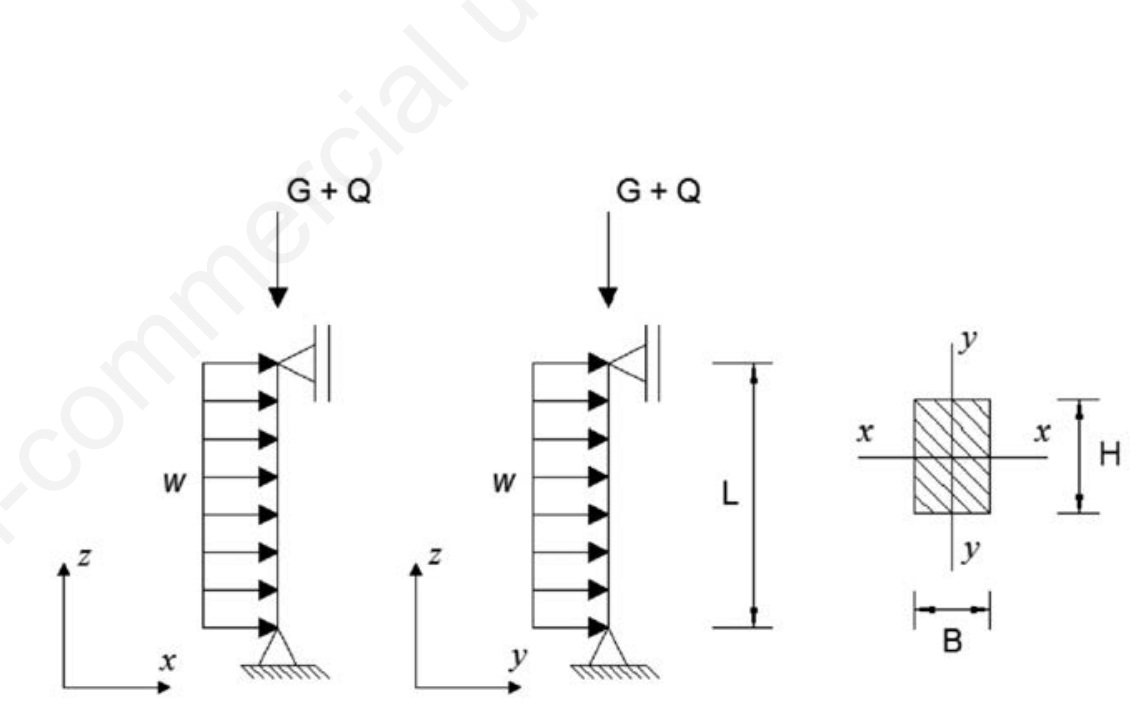

Figure 2. Structural diagram of the column.

\section{Results and Discussion}

In this section, the reliability analysis of each limit state equation is presented. Then, the column overall probability of failure based on the series association of the isolated failure criteria is discussed. Finally, the sensitivity analysis of the random variables is shown, indicating the most important random variables for each criterion.

\section{Structural reliability for the com- pression criterion}

The reliability index curves of the columns for the compression criterion (Eq. 6) are shown in Figure 3. Although the columns have the same cross-section areas, the one with the highest $B / H$ ratio has higher reliability indexes for a greater fire exposure time. The cross-section with the lowest $B / H$ ratio, equal to 0.20 , leads to the lowest reliability index, due to the larger perimeter available for the cross-section charring. There is also a larger time difference from the reliability index curves of $B / H$ ratios equal to 0.20 and 0.40 compared to the other ratios.

Table 1. Probabilistic input parameters of the random variables.

\begin{tabular}{|c|c|c|c|c|c|c|}
\hline Random variable & Symbols & Units & $\begin{array}{l}\text { Probability } \\
\text { distributions }\end{array}$ & Mean $(\mu)$ & $\begin{array}{c}\text { Standard } \\
\text { Deviation }(\sigma)\end{array}$ & $\begin{array}{l}\text { Coefficient } \\
\text { of variation }\end{array}$ \\
\hline Permanent action & $G$ & $\mathrm{kN}$ & Normal & 50.00 & 10.00 & 0.20 \\
\hline Variable action & $Q$ & $\mathrm{kN}$ & Gumbel & 125.00 & 31.25 & 0.25 \\
\hline Dynamic wind pressure & $w$ & $\mathrm{kN} / \mathrm{m}$ & Lognormal & 6.39 & 1.28 & 0.2 \\
\hline Charring rate & $\beta_{\text {char }}$ & $\mathrm{mm} / \mathrm{min}$ & Lognormal & 0.6 & 0.1 & 0.17 \\
\hline Modulus of elasticity along the grain & $E_{c 0}$ & $\mathrm{kN} / \mathrm{cm}^{2}$ & Lognormal & 2067.00 & 254.00 & 0.12 \\
\hline Compression strength along the grain & $f_{c 0}$ & $\mathrm{kN} / \mathrm{cm}^{2}$ & Lognormal & 6.20 & 0.64 & 0.10 \\
\hline Model uncertainties & $X_{M}$ & - & Lognormal & 1.00 & 0.10 & 0.10 \\
\hline
\end{tabular}


Assuming a reliability index limit of $2.00,{ }^{1}$ the results indicate that the $B / H$ ratios of $1.00,0.80$ and 0.60 show the highest fire resistance: 89,87 and $82 \mathrm{~min}$, respectively. These results are quite close to one another. The cross-section with $B / H=0.20$ showed the lowest fire resistance: $50 \mathrm{~min}$.

\section{Structural reliability for the com- bined bending and compression cri- terion}

In Figure 4, the results for the limit state equation $g_{2}$, for the combined bending and compression criterion in the $x$ and $y$ directions (Eq. 8), are presented. In Figure 4A, for the wind action applied in the $y$ direction and the bending moment vector in the $x$ direction, the cross-section with $B / H=1.00$ was the one with the lowest reliability indexes, an opposite result to the one found in the compression criterion. The highest cross-section is more effective in resisting lateral load applied in the $y$ direction. Initially, the curve of the $B / H=0.20$ presents the highest reliability index but, at 26 min, it intercepts the curve of the $B / H=$ 0.40 , quickly reaching the lowest performance at $58 \mathrm{~min}$ of fire exposure. The smaller base dimension and the larger height lead to a larger fire exposure perimeter, resulting in the rapid consumption of the cross-section. The $B / H=0.40$ presents the best fire resistance with failure time equal to $51 \mathrm{~min}$.

In Figure 4B, for the wind action applied in the direction of $x$ and bending moment vector in the $y$ direction, the results indicate that the $B / H$ ratios of $1.00,0.80$ and 0.60 show the best performance to fire exposure: 40, 35 and $30 \mathrm{~min}$, respectively. The cross-section with a $B / H$ ratio of 0.20 showed the lowest performance: $5 \mathrm{~min}$.

\section{Structural reliability for the lateral stability failure criterion}

The reliability indexes for the lateral stability in the $x$ and $y$ directions are shown in Figure 5. In Figure 5A, the cross-sections with the lowest $B / H$ ratios were those with the highest reliability indexes, a similar result to the one obtained for the combined bending and compression criterion. The reliability indexes of the lateral stability criterion are lower than those of the combined bending and compression criterion. As for the combined bending and compression criterion, the curve of $B / H=0.20$ intercepts the curve of the $B / H=0.40$ at $48 \mathrm{~min}$. Also, for $B / H=0.20$, there is a considerable reduction of the reliability index with relation to the other curves, reaching the limit at $39 \mathrm{~min}$.

In Figure 5B, the cross-section with the highest $B / H$ ratio presents a higher reliabil- ity index. This criterion has the lowest reliability indexes of all criteria in this study. The columns with $B / H$ ratios of $1.00,0.80$ and 0.60 show fire resistances equal to 18 , 12 and $5 \mathrm{~min}$, respectively. Curves of $B / H$ equal to 0.20 and 0.40 do not reach the minimal fire resistance prescribed in fire situation, even at an exposure time equal to zero.

\section{Column overall structural reliability}

In Figure 6A, the evaluation of the overall reliability indexes are presented as a function of the fire exposure time of the various column configurations. The indexes were obtained by the series association of the failure criteria. Only the lower bound of the series association is presented, since the bounds had similar values. This analysis led to similar results to those obtained for the lateral stability criterion in the $y$ direction (Figure 5B), indicating that this criterion is

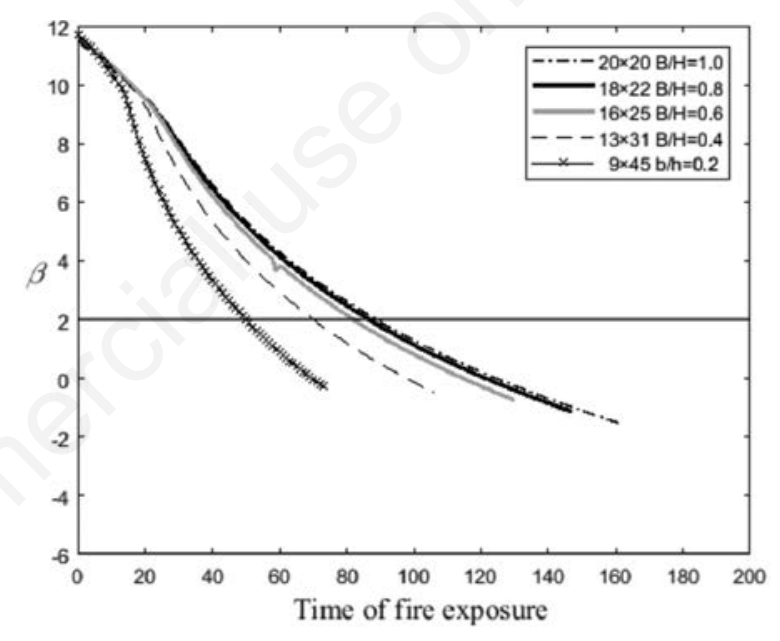

Figure 3. Reliability indexes for the compression criterion.
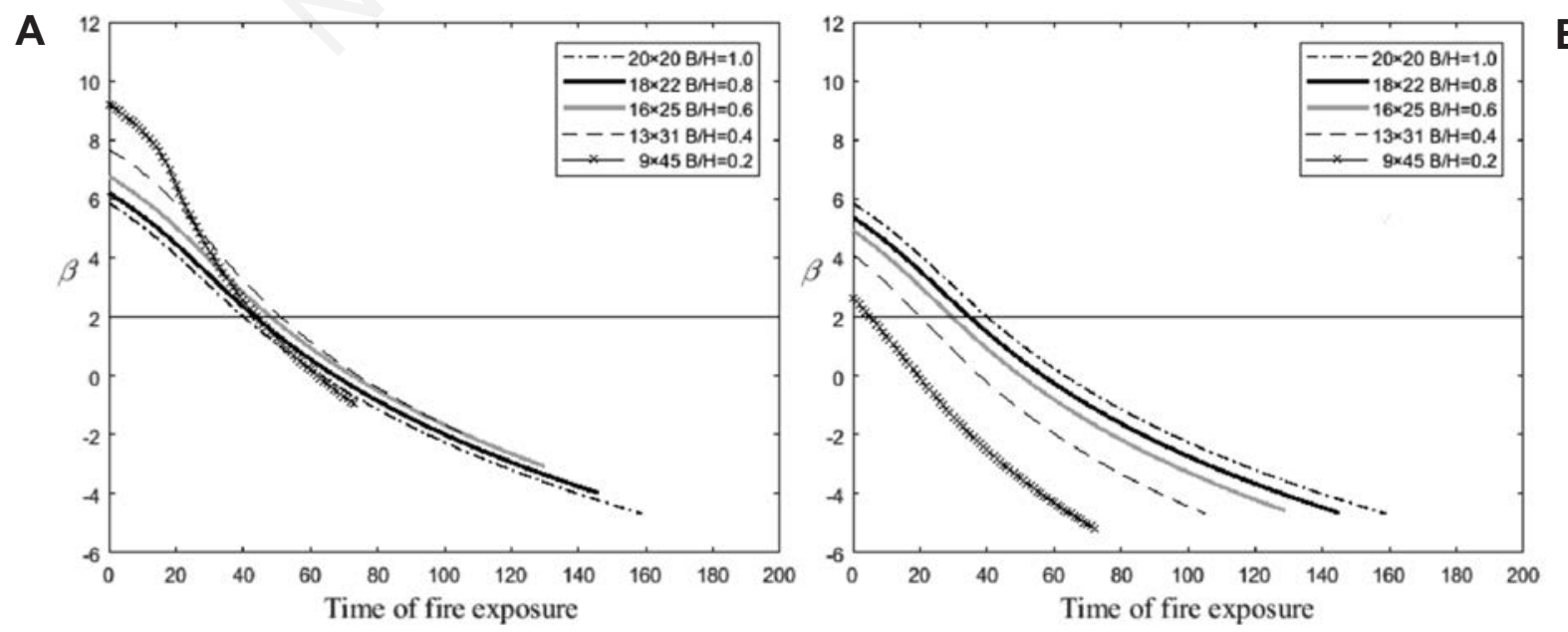

Figure 4. Reliability indexes for the combined bending and compression criterion: vector bending moment in the $\mathrm{x}$ direction (A) and in the $y$ direction (B). 
the most relevant in the analysis of columns. The reliability indexes reduce with the decrease of the $B / H$ ratio, and the $B / H$ ratio of 1.00 has the best performance.

Considering a limit reliability index equal to 2.00 for fire situation, ${ }^{1}$ the columns with $B / H$ ratios of $1.00,0.80$ and 0.60 have fire resistances of 18,12 and $5 \mathrm{~min}$, respectively. Curves of $B / H$ ratios equal to 0.20 and 0.40 do not reach the minimal fire resistances prescribed in fire situation, even at an exposure time equal to zero. This information could be useful to the Brazilian standard, in order to prescribe design criteria for columns in fire situation, since the knowledge of the overall structural reliability evolution along the time of fire exposure allows decision-making based on previously agreed reliability indexes. Further studies about cross-section $B / H$ ratios are required to obtain shape coefficients that could be used in new version of the Brazilian standard to define design criteria for timber columns in a fire situation, ensuring previously agreed structural reliability.

\section{Sensitivity of the random variables}

In Figures 6B-8, the sensitivity analysis of the critical situation is presented for the column with a cross-section of $16 \mathrm{~cm} \times 25$ $\mathrm{cm}$. For the compression criterion (Figure $6 \mathrm{~B}$ ), in the initial period of fire exposure, the most important variables are the variable action, the compression strength along the grain and the model uncertainties, in this order. For the combined bending and compression criterion (Figure 7), in the initial period of the fire exposure, the wind action is the most important variable. For the lateral stability criterion in the $x$ and y directions, variable and wind actions are the most important variables at the initial period of fire expo- sure. For all the criteria presented, throughout the fire exposure period, the charring rate becomes the most important variable.

\section{Conclusions}

In this paper, a structural reliability analysis of different configurations of timber columns was performed in a fire situation. This analysis was based on the failure criteria of compression, lateral stability and combined bending and compression, using the reduced cross-section and the FORM methods. The knowledge of the overall structural reliability evolution along the time of fire exposure allows, in design processes, decision-making based on previously agreed limit reliability indexes. For a limit reliability index of 2.00 , the obtained results allow to conclude that: i) the cross-
A

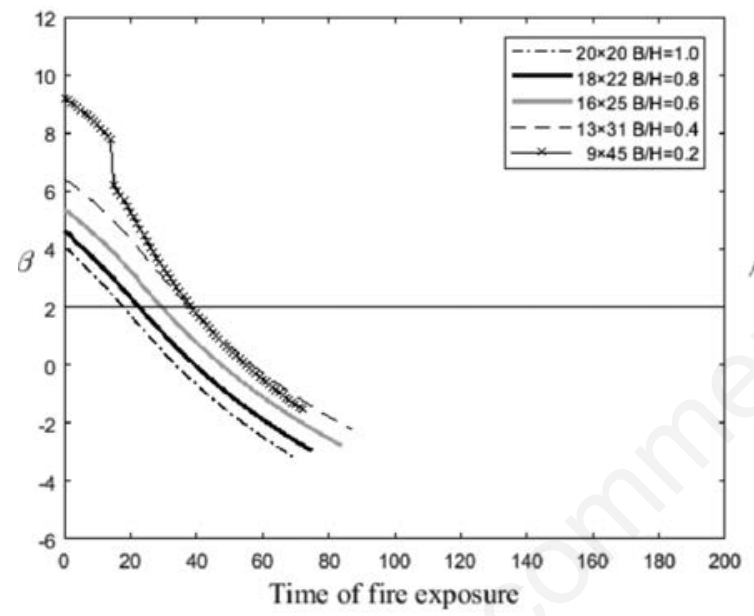

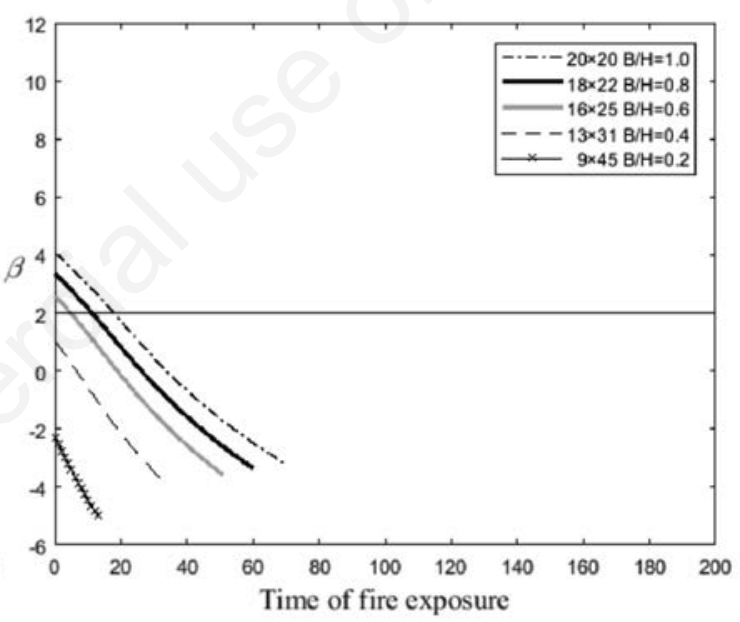

Figure 5. Reliability indexes for the lateral stability criterion: $x$ direction (A) and $y$ direction (B).

A

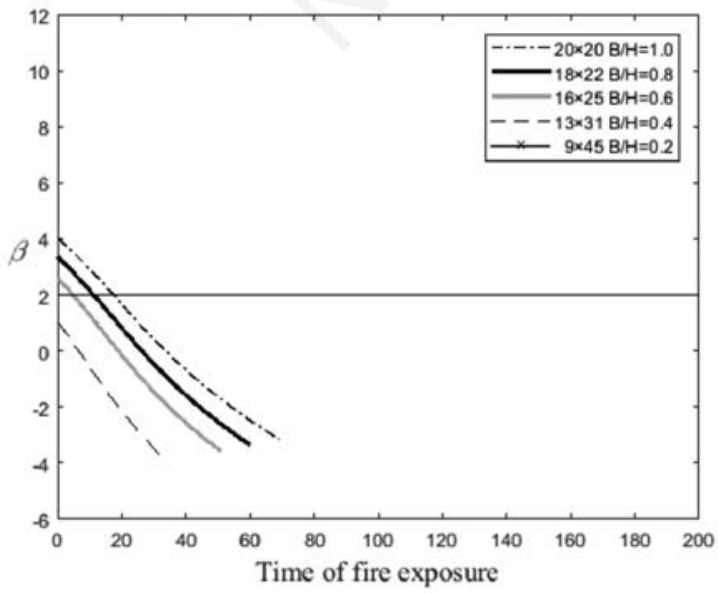

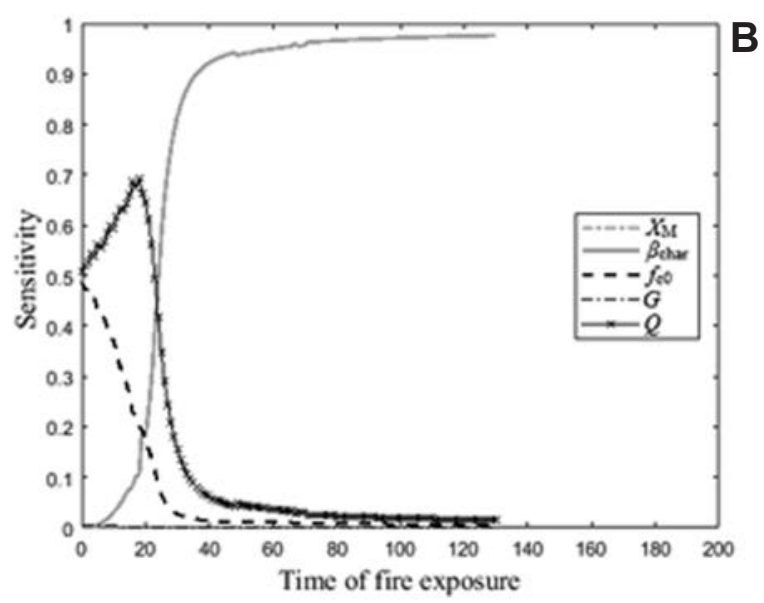

Figure 6. (A) Reliability indexes for the failure criteria associated in series; (B) Sensitivity analysis of the $16 \mathrm{~cm} \times 25 \mathrm{~cm}$ cross-section for the compression criterion. 
A
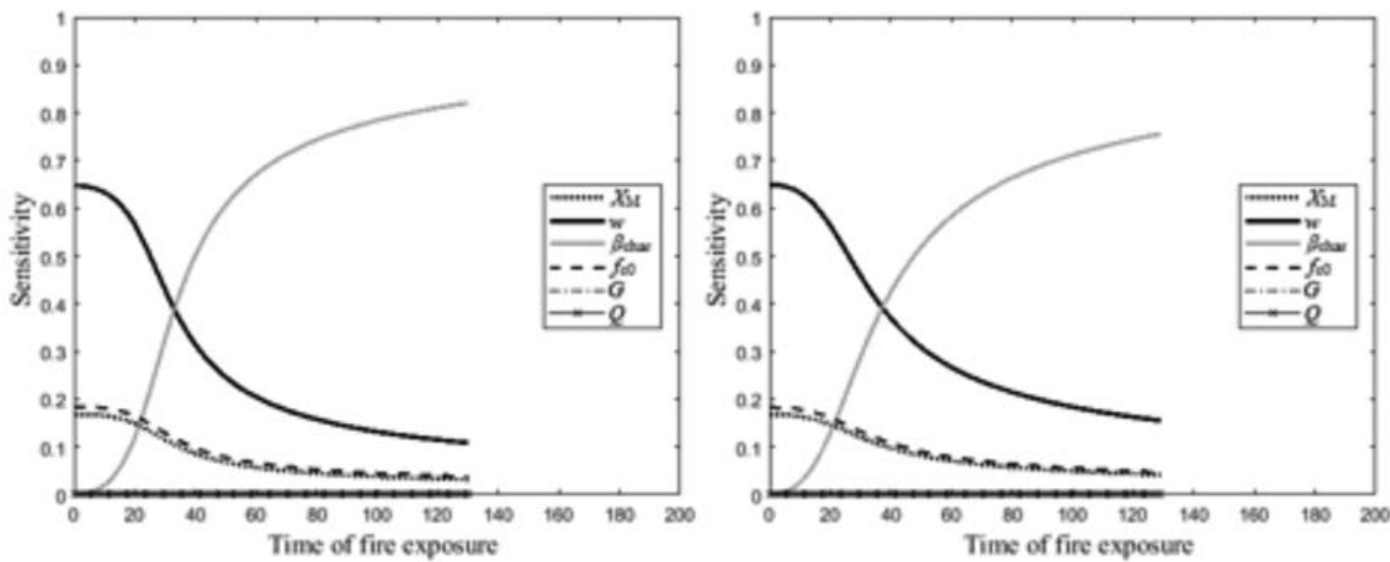

Figure 7. Sensitivity analysis of the $16 \mathrm{~cm} \times 25 \mathrm{~cm}$ cross-section for the combined bending and compression criterion: bending in the $x$ direction (A) and bending in the $y$ direction (B).
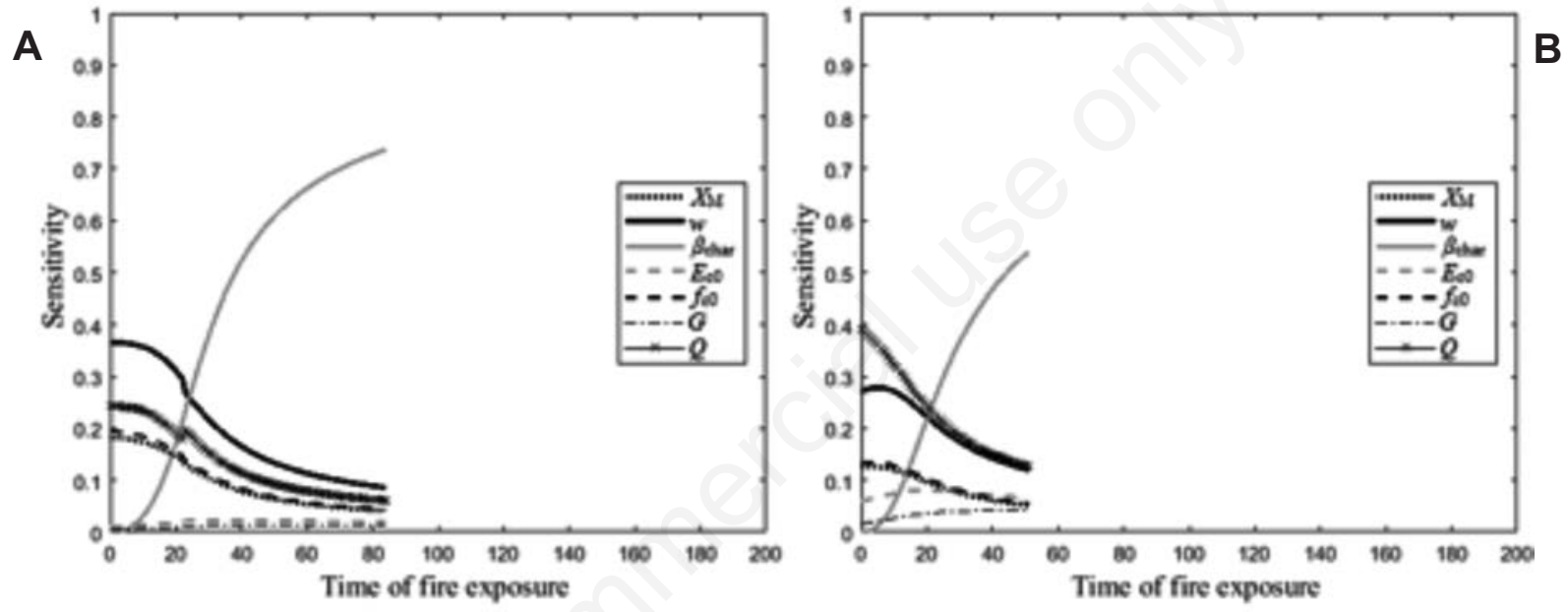

Figure 8. Sensitivity analysis of the $16 \mathrm{~cm} \times 25 \mathrm{~cm}$ cross-section for the lateral stability criterion: direction $x$ (A) and direction $y$ (B).

section $B / H$ ratio is an important parameter to ensure the structural safety of compressed columns; ii) the highest values for the overall structural reliabilities were presented by the cross-section with $\mathrm{B} / \mathrm{H}$ ratios of $1.00,0.80$ and 0.60 ; iii) the series association of the failure criteria presents similar results to the lateral stability criterion in the $y$ direction, confirming that it is the most relevant criterion in the design of the columns in a fire situation; iv) the variable and the wind actions are the random variables that present the greatest influence on the reliability analyses in the initial fire exposure period. However, the charring rate becomes the most important random variable as the fire exposure time increases; v) studies about cross-section $B / H$ ratios should be developed to obtain shape coefficients to be used in the design of columns in a fire situation in order to ensure the limit reliability index.

\section{Nomenclature}

$b$ base dimension of the residual crosssection $(\mathrm{m})$

$B$ base dimension of the original crosssection $(\mathrm{m})$

$d$ cross-section height of the verification plane $(\mathrm{m})$

$h$ height dimension of the residual cross-section (m)

$H$ height dimension of the original cross-section (m)

$E_{\mathrm{i}} \quad$ failure of the $\mathrm{i}^{\text {th }}$ component in series

$e_{1, \text { ef }}$ first-order supplementary eccentricity $(\mathrm{m})$

$e_{\mathrm{a}} \quad$ accidental eccentricity (m)

$e_{\mathrm{d}}$ design eccentricity $(\mathrm{m})$

$e_{\mathrm{i}} \quad$ initial eccentricity $(\mathrm{m})$

$F \quad$ system failure event

$f_{\mathrm{c} 0} \quad$ compressive strength along the grain $\left(\mathrm{kN} / \mathrm{m}^{2}\right)$

$F_{\mathrm{E}} \quad$ Euler's critical load $(\mathrm{kN})$

$E_{\mathrm{c} 0} \quad$ modulus of elasticity along the grain
$\left(\mathrm{kN} / \mathrm{m}^{2}\right)$

$G \quad$ permanent action $(\mathrm{kN})$

$I$ second moment of area of the resistant cross-section $\left(\mathrm{m}^{4}\right)$

$L \quad$ column length (m)

$L_{0} \quad$ theoretical reference length (m)

$M \quad$ bending moment (kN.m)

$N \quad$ axial load $(\mathrm{kN})$

$P_{\mathrm{f}} \quad$ probability of failure

$Q \quad$ variable action $(\mathrm{kN})$

$t \quad$ time of fire exposure (min)

$V_{\mathrm{k}} \quad$ characteristic wind speed $(\mathrm{m} / \mathrm{s})$

$w \quad$ dynamic wind pressure $(\mathrm{kN} / \mathrm{m})$

$W_{\mathrm{c}}$ cross-section modulus $\left(\mathrm{m}^{3}\right)$

$y_{c}$ distance of the neutral line to the most compressed grain $(\mathrm{m})$

$X_{\mathrm{m}} \quad$ factor for the model uncertainties

$\beta \quad$ reliability index

$\beta_{\text {char }}$ charring rate $(\mathrm{m} / \mathrm{min})$

$\lambda$ slenderness ratio of the element

$\sigma_{\mathrm{Nc}} \quad$ compressive stress $\left(\mathrm{kN} / \mathrm{m}^{2}\right)$

$\sigma_{\mathrm{M}}$ maximum bending stress in the one 
direction $\left(\mathrm{kN} / \mathrm{m}^{2}\right)$

$\Phi \quad$ creep coefficient

$\Phi($.$) standard normal cumulative distribu-$ tion function

$\Psi_{1} \quad$ load combination factor

$\Psi_{2}$ use combination factor

\section{References}

1. Buchanan AB, Abu AK. Structural design for fire safety. 2nd ed. Chichester, UK: Wiley; 2017.

2. Melchers RE, Beck AT. Structural Reliability analysis and prediction. 3rd ed. New York, NY: Wiley; 2018.

3. Kohler J. Reliability of Timber Structures. PhD Thesis. Swiss Federal Institute of Technology; 2007.

4. Vaidogas ER, Juoceicius V. Reliability of a timber structure exposed to fire: estimation using fragility function. Mechanika 2008;5:35-42.

5. Cheung AB, Pinto EM, Calil CJ. Confiabilidade estrutural de vigas de madeira submetidas à flexão em condições normais e em situação de incêndio. Madeira Arquit Engen 2011;12:1-12.

6. Clancy P. Time and probability of failure of timber framed walls in fire. $\mathrm{PhD}$ Thesis. Victoria University of Technology; 1999.

7. Associação Brasileira de Normas Técnicas, 1997. NBR 7190: Design of wooden structures. Rio de Janeiro, BR; 1997.

8. Ditlevse O, Madsen HO. Structural reliability methods. Department of Mechanical Engineering, Technical University of Denmark, Copenhagen;
2007.

9. Sorensen JD. Notes in structural reliability: theory and risk analysis. Aalborg, Denmark; 2004.

10. Associação Brasileira de Normas Técnicas. Revisão NBR 7190: Design of wooden structures. Rio de Janeiro, BR; 2011.

11. Mahsuli M, Haukaas T. Computer program for multimodel reliability and optimization analysis. ASCE J Comput Civil Engin 2013;27:87-98.

12. Associação Brasileira de Normas Técnicas. NBR 6123: Building construction - Bases for design of structures - Wind loads Procedure. Rio de Janeiro, BR; 1988.

13. Joint Committee on Structural Safety. JCSS: Probabilistic Model Code. Copenhagen, Denmark; 2015. 